\title{
Superhydrophobic organic-inorganic thin films on aluminum by a simple one-step electrochemical process
}

\author{
$\mathrm{Na} \mathrm{X \mathbf {u } ^ { 1 , 2 }}$, Sarkar $\mathrm{DK}^{2}$, Chen $\mathrm{XG}^{2}$ and Tong $\mathrm{W}^{1}$ \\ ${ }^{1}$ Key Laboratory of National Education Ministry for Electromagnetic Processing of Materials, Northeastern University, Shenyang, China \\ ${ }^{2}$ Centre Universitaire de Recherche sur l'Aluminium (CURAL), Université du Québec à Chicoutimi, 555 Boulevardl'Université, Chicoutimi, Québec, Canada
}

\begin{abstract}
An ethanolic solution containing copper nitrate salt and stearic acid (SA) organic molecules have been used to perform electrochemical modification of aluminum surfaces using a DC voltage to render them superhydrophobic in a one-step process. The formation of low surface energy copper stearate thin film having rose petal like micro-nano morphology is the driving force on the roll-off properties of water drops on these surfaces providing superhydrophobic properties with water contact angle of $162 \pm 1^{\circ}$, and an excellent corrosion resistance property.
\end{abstract}

\section{Introduction}

Wettability is one of the most important surface prosperities of the solid materials, which is governed by both the chemical composition and geometric structure of a surface. In nature, the most widely known example is the lotus leaf owing its self-cleaning properties due to the coexistence of micro-nanostructure and low surface energy waxy coating that weakens the electrostatic interaction between water and surface [1]. Due to the versatile applications of superhydrophobic surfaces researchers all around the world is are continuously working in this field of research [2-6]. Our group is actively working in the fabrication of superhydrophobic surfaces on aluminum and other metal surfaces using different techniques [7-17]. For example, we have previously shown that copper surfaces can be made superhydrophobic by a simple one-step electrochemical process. This one-step procedure, is not only low cost, facile and effective, but the micro-nanostructured texture of the surface can also be easily controlled by regulating the parameters of electrodeposition such as the electrolytes concentration, deposition time and applied DC voltage $[12,17]$. However, this method failed to modify the aluminum surfaces superhydrophobic as aluminum is not reactive like copper and does not produce aluminum stearate by this method [16]. Therefore, initially we electrodeposited microdots of copper on aluminum surface and then modified the copper deposited aluminum surface using the electrochemical process which resulted in superhydrophobic properties, however, employing more than one step in the fabrication process [15].

In this letter, this complexity has been overcome and a solution has been provided to obtain superhydrophobic aluminum surfaces by a one-step electrochemical modification of aluminum substrates in an ethanolic stearic acid solution containing copper nitrate salt. Chemically cleaned aluminum plates were taken as both cathode and anode in an ethanolic stearic acid (SA) and copper nitrite mixed solution and a DC voltage of $10 \mathrm{~V}$ was applied to the electrodes separated by a distance of $1.5 \mathrm{~cm}$. The molar ratio of $\mathrm{Cu}^{+2} / \mathrm{SA}$ was kept to a constant value of 0.5 in this present work. The process resulted in the growth of a thin film on the cathodic electrode. The morphological chemical and wettability analysis on the electrochemically growth thin films on aluminum surfaces were performed using the morphological analyses of the samples were performed using a scanning electron microscope (SEM, JEOL JSM-6480 LV). Optical profilometry (model: was also used to measure the topography and surface roughness. The chemical composition was analyzed by X-ray diffraction (XRD, D8 discover with $\mathrm{Cu} \mathrm{Ka}$ wavelength $0.154 \mathrm{~nm}$ ) and Fourier Transform Infrared spectroscopy (FTIR, Agilent Cary 630). The wetting characterization of the sample surfaces was carried out by measuring static and dynamic contact angles using a First Ten Angstrom contact angle goniometer (the static contact angle has been abbreviated as CA and the dynamic contact angle has been abbreviated as contact angle hysteresis (CAH)). The corrosion studies were performed by electrochemical impedance spectroscopy (EIS) in the frequency range between $10 \mathrm{mHz}$ and 100 $\mathrm{kHz}$ with a sine-wave amplitude of $10 \mathrm{mHz}$ using $3.5 \mathrm{wt} . \% \mathrm{NaCl}$ aqueous solution.

\section{A optimization process}

Figure 1a shows high angle x-ray diffraction (XRD) spectrum of the thin film on aluminum surface deposited for $10 \mathrm{~min}$ and Figure 1b, the inset of Figure 1a, shows the low angle XRD spectrum of the same. The high angle XRD shows four characteristic peaks of aluminum [18] and the low angle XRD spectrum prove that the thin film is the copper stearate as we reported earlier on copper surfaces $[12,19]$ The characteristic copper stearate peaks are identified by triangular legends in Figure1b. Figure 1c shows the FTIR spectra of chemically cleaned $\mathrm{Al}$ substrate and that of the thin films on aluminum surfaces prepared with varying times of 1,10 and 60 minutes. Due to the metallic nature of the chemically cleaned Al surface, no characteristic peaks of FTIR are

Correspondence to: DSarkar DK, Centre Universitaire de Recherche sur l'Aluminium (CURAL), Université du Québec à Chicoutimi, 555 Boulevardl' Université, Chicoutimi, Québec, Canada

Key words: electrochemical modification, thin films, surface morphology, superhydrophobic aluminum surfaces, corrosion resistance properties

Received: May 01, 2017; Accepted: May 17, 2017; Published: May 22, 2017 

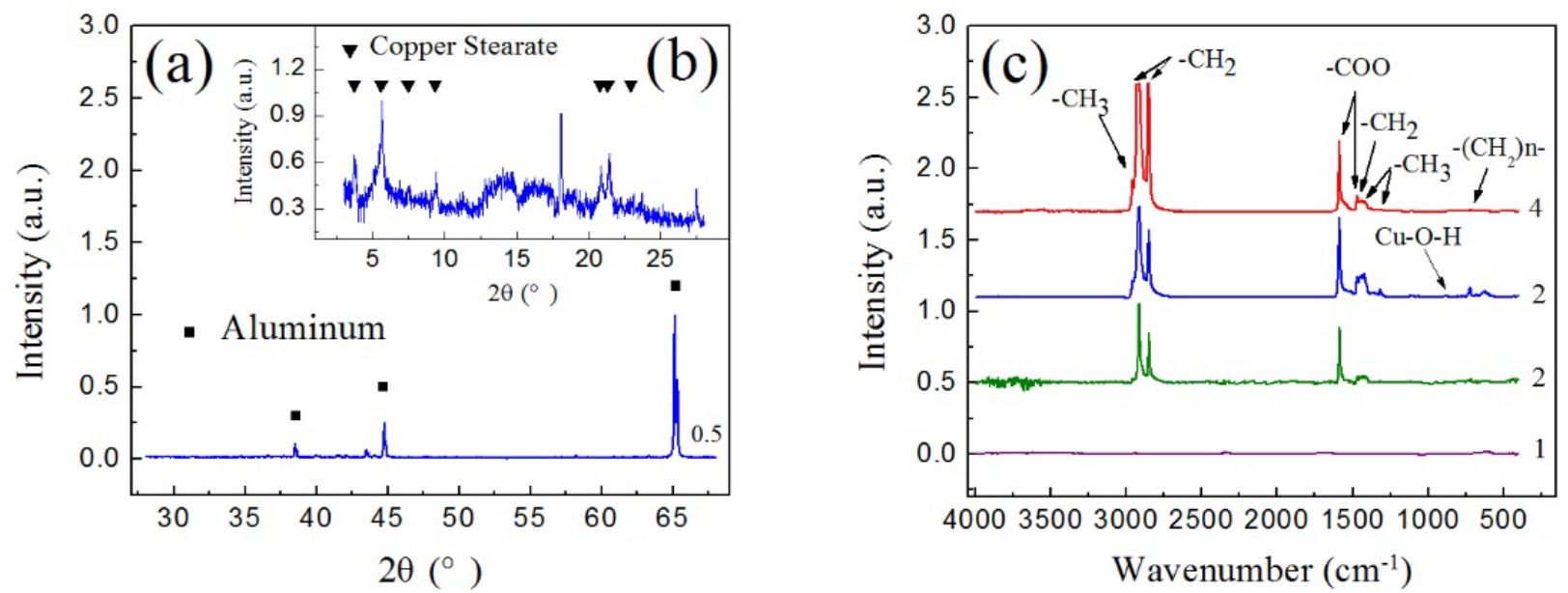

Figure 1. (a, b) XRD spectra, both high and low angle, of thin films on aluminum surface (c) The FTIR spectra (1) chemically cleaned Al substrate, and superhydrophobic aluminum surface prepared for (2) $1 \mathrm{~min}$, (3) $10 \mathrm{~min}$ and (4) $60 \mathrm{~min}$;

visible (Figure 2c-1) on this surface indicating the removal of the native oxide of aluminum. This is also due to the fact of the detection limit of FTIR to probe the native surface oxide. On the other hand, Figures 1c2,3 and 4 of the thin films on aluminum surfaces show intense bands centered at $2954 \mathrm{~cm}^{-1}, 2918 \mathrm{~cm}^{-1}$ and $2848 \mathrm{~cm}^{-1}$ these are assigned to be the asymmetric stretching of $-\mathrm{CH}_{3}$ as well as symmetric and asymmetric stretching vibrations of $-\mathrm{CH}_{2}$ from stearic acid [17]. The peaks at the $1589 \mathrm{~cm}^{-1}$ and $1467 \mathrm{~cm}^{-1}$ are attributed to the $-\mathrm{COO}$ band due to the formation of thin films of copper stearate on the aluminum surface [17]. These spectra also show that the intensity of these peaks increases with the increase in the time of electrochemical modification. The presence of these peaks confirms the formation of the low surface energy copper stearate which is agreement with our previous report on copper surfaces [17]. Based on these analyses, a probable formation mechanism thin film of copper stearate on the aluminum surface can be derived as follows:

$$
\mathrm{Cu}^{+2}+4 \mathrm{COOH}-(\mathrm{SAl})=2 \mathrm{Cu}(\mathrm{COO}-\mathrm{SAl})_{2}+4 \mathrm{H}_{2}
$$

where, the compound $\mathrm{Cu}(\mathrm{COO}-\mathrm{SA} 1)$ is called copper stearate, where $\mathrm{SA} 1=-\left(\mathrm{CH}_{2}\right)_{16}-\mathrm{CH} 3$.

The Scanning Electron Microscopy (SEM) image of the chemically cleaned aluminum surface presented in Figure 2a shows that the surface is composed of round micro-nano craters of varied sizes. The inset of Figure 2a shows the image of water drop with a contact angle (CA) of $54^{\circ}$. SEM image in Figure $2 \mathrm{~b}$ shows the morphological feature of the copper stearate thin films on aluminum surface grown for 1 minute in the form of microflowers of diameter less than $5 \mu \mathrm{m}$ assembled with many nanoscaled features. The inset of Figure $2 b$ shows the image of water drop with a contact angle (CA) of $144^{\circ}$. It can be seen from the Figure $2 c$ that the aluminum substrate is completely covered by the copper stearate thin films presenting a rose-petal-like microstructured morphology when the electrochemical modification time is increased to $10 \mathrm{~min}$. The standing micronano-petals construct the porous structure that entraps the air beneath a water drop hence enhancing the roll off properties of the superhydrophobic surfaces providing water contact angle of $162 \pm 1^{\circ}$ (in the inset of Figure $2 \mathrm{c}$ and a water contact angle hysteresis $(\mathrm{CAH})$ below $1.7 \pm 1^{\circ}$. The prolongation of electrochemical modification time to 60 min leads to a compact thin film Figure $2 \mathrm{~d}$ with the absence of the rose-petal-like microstructures leaving no room for entrapment of air to boost the water drop roll-off property. Consequently, the water contact angle reduced to $\sim 145$ (in the inset of Figure $2 \mathrm{~d}$ with $\mathrm{CAH}$ above $10^{\circ}$ on this compact surface. As evident from the time dependent morphological evolution, the surface roughness of these surfaces also increase with the increase of electrodeposition time from 0 to $10 \mathrm{~min}$ and then decrease with further prolongation of modification time to $60 \mathrm{~min}$ complementing the morphological behavior. The roughness, measured by optical profilometry, reached to the highest value of $\sim 3.61 \mu \mathrm{m}$ when the deposition time was $10 \mathrm{~min}$. Figure $2 \mathrm{e}$ shows the variation of the water contact angle (CA) with the electrochemical modification time indicating the optimum deposition time to be 10 minutes to obtain the best superhydrophobic properties. Figure $2 \mathrm{f}$ shows the Nyquist plots, one of the presentations of EIS studies, a graphical presentation of real part of the impedance, Z', vs imaginary part of the impedance, Z'. The charge transfer resistance (Rct) as derived from these plots are found to be $1130 \mathrm{k} \Omega \mathrm{cm}^{2}$ and $1.56 \mathrm{k} \Omega \mathrm{cm}^{2}$ for the superhydrophobic thin films on aluminum grown for $10 \mathrm{~min}$ and aluminum substrate, respectively. It can be noted that the value of the Rct for superhydrophobic surface is 700 times larger than that of the chemically cleaned Al. In a recent work by Liu et al. [20], the Rct of the superhydrophobic cerium containing myristic acid on copper alloys (brass) was reported to be 10 times larger than their as-received brass substrate. It is to be noted that the Nyquist plots of both superhydrophobic thin films on aluminum and aluminum substrate have a linear part at low frequencies (last few data in the graphs) due to the capacitive nature of these surfaces in corrosion environment associated to Warburg impedance. A complete study on the effect of composition as well as potential on the superhydrophobic and corrosion properties is currently in-progress to be communicated as a regular article.

A facile one-step electrochemical modification process has been developed to prepare superhydrophobic aluminum surfaces via electrochemical modification using an ethanolic solution containing copper nitrite and stearic acid. The surface morphology, roughness and wetting properties are found to vary with the electrochemical modification time. The optimum surface presenting the best superhydrophobic properties consists of rose petal-like microstructures of copper stearate, as evident from FTIR and XRD analysis, contributing to a very high water contact angle of $162 \pm 1^{\circ}$ 

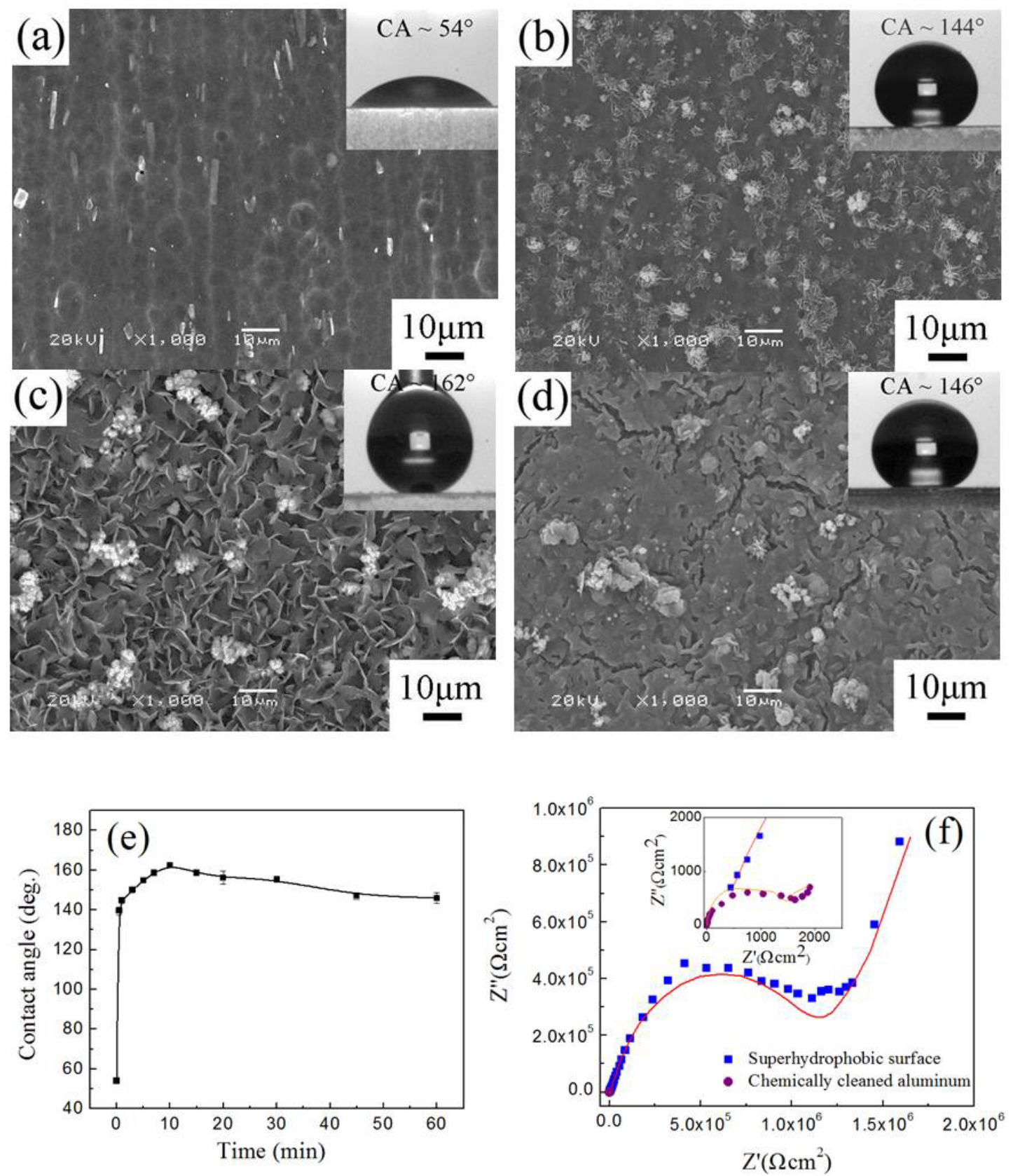

Figure 2. SEM images of (a) chemically cleaned aluminum substrate; and electrochemically modified aluminum substrates at $10 \mathrm{~V}$ for (b) 1 min, (c) 10 min and (d) 60 min, keeping the molar ratio of $\mathrm{Cu}^{+2} / \mathrm{SA}$ equal to 0.5 ; (e) variation of water contact angle (CA) with electrodeposition time, (f) Electrochemical impedance spectroscopy (EIS), Nyquist plots, of chemically cleaned aluminum, as (a) and superhydrophobic surface as (c).

with excellent water drop roll-off properties. The electrochemical impedance spectroscopy (EIS) analysis shows that the charge transfer resistance of the superhydrophobic surface is $1360 \mathrm{k} \Omega-\mathrm{cm}^{2}$ which is 700 times larger than the chemically cleaned aluminum surface.

\section{Acknowledgement}

We acknowledge the financial support provided by the Natural Science and Engineering Research Council of Canada (NSERC).

\section{References}

1. Neinhuis C, Barthlott W (1997) Ann Bot 79: 667-677.
2. Bird JC, Dhiman R, Kwon HM, Varanasi KK (2013) Reducing the contact time of a bouncing drop. Nature 503: 385-388. [Crossref]

3. Chen SS, Li X, Li Y, Sun JQ (2015) Intumescent flame-retardant and self-healing superhydrophobic coatings on cotton fabric ACS Nano 9: 4070-4076.

4. Ramachandran R, Sobolev K, Nosonovsky M (2015) Dynamics of droplet impact on hydrophobic/icephobic concrete with the potential for superhydrophobicity. Langmuir 31: 1437-1444. [Crossref]

5. Hatton BD, Aizenberg J (2012) Writing on superhydrophobic nanopost arrays: topographic design for bottom-up assembly. Nano Lett 12: 4551-4557. [Crossref]

6. Lu Y, Sathasivam S, Song J2, Crick CR3, Carmalt CJ, et al. (2015) Repellent materials Robust self-cleaning surfaces that function when exposed to either air or oil. Science 347: 1132-1135. [Crossref] 
7. Brassard JD, Sarkar DK, Perron J (2011) Synthesis of monodisperse fluorinated silica nanoparticles and their superhydrophobic thin films. ACS Appl Mater Interfaces 3: 3583-3588. [Crossref]

8. Sarkar DK, Farzaneh M, Paynter RW (2008) Fabrication of Superhydrophobic Nanocomposite Coatings Using Polytetrafluoroethylene and Silica Nanoparticles. Mater Lett 62: 1226-1229.

9. Saleema N, Sarkar DK, Paynter RW, Chen XG (2010) Superhydrophobic aluminum alloy surfaces by a novel one-step process. ACS Appl Mater Interfaces 2: 2500-2502. [Crossref]

10. Siddaramanna A, Saleema N, Sarkar DK (2014) A versatile cost-effective and one step process to engineer $\mathrm{ZnO}$ superhydrophobic surfaces on Al substrate. Appl Surf Sci 311: 182-188.

11. Brassard JD, Sarkar DK, Perron J (2015) Studies of drag on the nanocomposite superhydrophobic surfaces. Appl Surf Sci 324: 525-531.

12. Huang Y, Sarkar DK, Chen XG (2010) A one-step process to engineer super hydrophobic copper surfaces Mater Lett 64: 2722-2724.

13. Brassard JD, Sarkar DK, Perron J, Audibert-Hayet A, Melot D (2015) Nano-micro structured superhydrophobic zinc coating on steel for prevention of corrosion and ice adhesion. J Colloid Interface Sci 447: 240-247. [Crossref]
14. Huang Y, Sarkar DK, Chen XG (2015) A one-step process to engineer superhydrophobic copper surfaces Appl Surf Sci 327: 327-334.

15. Huang Y, Sarkar DK, Chen XG (2011) Fabrication of Superhydrophobic Surface on Aluminum Alloy Via Electrodeposition of Copper Followed by Electrochemical Modification. Nano-Micro Lett 3: 160-165.

16. Huang Y (2012) Master Thesis Study On The Degradation Mechanism Of HeatTreated Wood By Uv Light, University of Quebec At Chicoutimi.

17. Huang Y, Sarkar DK, Chen XG (2013) Fabrication of Corrosion Resistance Micro-Nanostructured Superhydrophobic Anodized Aluminum in a One-Step Electrodeposition Process. Appl Surf Sci 282: 689-694.

18. Ying Huang, Sarkar DK, X-Grant Chen (2011) Fabrication of Superhydrophobic Surfaces on Aluminum Alloy Via Electrodeposition of Copper Followed by Electrochemical Modification. Aluminum JCPDS 085-1327.

19. Na Xu, Sarkar DK, Hui Zhanga X, Tong W (2016) Superhydrophobic copper stearate/copper oxide thin films by a simple one-step electrochemical process and their corrosion resistance properties. Copper stearate JCPDS 055-1622.

20. Liu CS, Su FH, Liang JZ, Huang P (2014) Phase Transition Enthalpy Measurements of Organic and Organometallic Compounds and Ionic Liquids. Sublimation, Vaporization, and Fusion Enthalpies from 1880 to 2015. Surf Coat Tech 258: 580-586.

Copyright: (C2017 Xu N. This is an open-access article distributed under the terms of the Creative Commons Attribution License, which permits unrestricted use, distribution, and reproduction in any medium, provided the original author and source are credited. 